\title{
HPV-Mediated (p16-Positive) Oropharyngeal Cancer pT3 TNM Finding \\ v8
}

National Cancer Institute

\section{Source}

National Cancer Institute. HPV-Mediated (p16-Positive) Oropharyngeal Cancer PT3 TNM

Finding v8. NCI Thesaurus. Code C132865.

HPV-mediated (p16-positive) oropharyngeal cancer with tumor larger than $4 \mathrm{~cm}$ in greatest dimension or extension to lingual surface of epiglottis. (from AJCC 8th Ed.) 